\title{
A Multilevel Comprehensive Assessment of International Accreditation for Business Programmes-Based on AMBA Accreditation of GDUFS
}

\author{
Yong Jiang ${ }^{1}$ \\ ${ }^{1}$ School of English for International Business, Guangdong University of Foreign Studies, Guangzhou, China \\ Correspondence: Yong Jiang, School of English for International Business, Guangdong University of Foreign \\ Studies, Room 317, No. 3 Teaching Building, 2\# North Baiyun Ave. Guangzhou, 510420, China. Tel: \\ 86-139-2957-1649. E-mail: jiangyong@gdufs.edu.cn
}

Received: August 11, 2017

Accepted: August 22, 2017

Online Published: September 20, 2017

doi:10.5539/hes.v7n4p15

URL: http://doi.org/10.5539/hes.v7n4p15

\begin{abstract}
Traditional mathematical methods built around exactitude have limitations when applied to the processing of educational information, due to their uncertainty and imperfection. Alternative mathematical methods, such as grey system theory, have been widely applied in processing incomplete information systems and have proven effective in a number of fields. In this study, an assessment indicator system is developed, based on the MBA programme of Guangdong University of Foreign Studies (GDUFS), through statistics building on the initial indicators of the Association of MBA's assessment system for MBA programmes. The proposed system assesses the accredited indicators of the GDUFS' MBA programme using grey comprehensive evaluation methodology. The results accord with the actual situation, supporting the accuracy of the assessment model, research theory and methodology. In addition, this paper analyses and sorts degrees of satisfaction for programme indicators, with the adoption of the grey correlation analysis method, to provide a basis for decision-making.
\end{abstract}

Keywords: multilevel comprehensive assessment, international accreditation, AMBA, business programmes

\section{Introduction}

In the development of the education sector of nearly all countries, the quality of higher education is always a focus for educators. Whether in developed or developing countries, people around the world are seek quality higher education, and demand an education system with guarantees for such quality; a system that is rational, transparent, and efficient. In this respect, the accreditation of institutions of higher education has proven effective. It provides external and independent supervision over the quality of higher education by thoroughly examining and assessing universities, colleges and majors.

There are many systems for the accreditation of institutes of higher education. Amongst them are the standard accreditations awarded for quality of higher education to universities and colleges. For instance, the three main international accreditations for business schools: the Association to Advance Collegiate Schools of Business (AACSB), the European Quality Improvement System (EQUIS), and the Association of MBAs (AMBA).

Since 2000, business schools in mainland China have begun to observe international accreditation systems, and many now see the systems' significance. In 2006, School of Management of Zhejiang University was awarded accreditation by the AMBA, becoming the first university in mainland China to receive the internationally recognized certification for business schools. The Financial Times reported this groundbreaking event with the headline "First Business School within Chinese System to be Internationally Accredited" and called it "a milestone in Chinese business education's course to gain international accreditation". Thereafter, Tsinghua University was awarded accreditation from the AACSB in 2007 and the EQUIS in 2008. Tsinghua University became the first university in China to receive both of these major accreditations.

Given the authority and exclusivity of accreditation systems, accreditation means global recognition for universities and their specific programs. Thus, a good number of business schools in different parts of the world are now queuing for accreditation, and an increasing number of Chinese business schools are joining the trend. As of April 2017, 19 business schools in mainland China have received the EQUIS accreditation, 18 from the AACSB, and 28 from the AMBA. Among them, the Antai College of Economics and Management of Shanghai 
Jiao Tong University, the School of Management of Zhejiang University, Sun Yat-sen Business School as well as Lingnan College of Sun Yat-Sen University have all passed the triple international accreditations. Many more universities are applying for accreditation and joining accreditation organizations.

In May 2015, the Master of Business Administration (MBA) programme of Guangdong University of Foreign Studies (GDUFS) was awarded accreditation. Through this process, the MBA programme has made great improvements in programme management, structure design, faculty, resource integration, subject development, curriculum, internationalization, self-assessment, teaching mode, and so on. This study will analyse the results of a satisfaction assessment regarding the GDUFS's accredited programme by adopting a multilevel grey assessment methodology, so as to provide insight for reaccreditation policy.

\section{Literature Review}

Judith S. Milton, chairman of the Council for Higher Education Accreditation (CHEA), pointed out that accreditation is the most fundamental method for institutions of higher education to guarantee and improve the quality of their education. The chairman noted that higher education accreditation plays four important roles: ensuring and improving quality of education, guaranteeing the academic value of higher education, avoiding political influence and intervention on education, and serving the public interest. Zhang Jianru (2006) studied the accreditation systems of the United States' AACSB, the United Kingdom's AMBA, and the European Union's EQUIS. The study compared the accreditation organizations' numbers, qualifications, processes, and standards for these systems. The research of Trapnell (2007), as well as some other scholars, discussed the benefits and value of the AACSB pushing through international accreditations. They found that accreditation is a helpful identifier of business education quality for students, teachers, and entrepreneurs. Hedrick (2010) carried out a quantitative study on international accreditation output, and the results indicated that teachers working for accredited business schools get higher salaries and published more research, when compared with their peers working for non-accredited schools.

Zhang (2009), conducting an assessment on government participation in higher education for the United States, the United Kingdom, and France, classified three categories of government participation therein: the social autonomous model, the government-guiding model, and the government-centralizing model, respectively. Crow (2009) pointed out that more research on accreditation organizations should be made on seven aspects, including strengthening peer coordination and cooperation, increasing transparency, clarifying basic objectives of accreditation, re-examining peer assessment methods, studying threats in peer assessment, creating interaction opportunities for low risk and high return amongst peers, and blazing new trails for funding. Zhang, J. R. and Zhang, Z. G. (2010) posited that professional accreditation organizations in the United States are mostly industry associations or institutions developed from trade associations. This makes them more acceptable for professional-oriented universities, as well as more attractive to professional managers for participation. Their unofficial nature helps accreditation organizations better fulfil their obligations to make unbiased assessments.

Hazen, Cavanagh and Bossman (2004) noted that over the past decade, international accreditation organizations have encouraged business schools to carry out curriculum development within the context of their respective programme objectives. Jantzen (2000) and Yunker (2000) interviewed business school deans and concluded that the different objectives for different colleges help to generate unique characteristics and diversity in their programme curricula. After studying the accreditation system of the AACSB, Shaftel (2007) argued that it provides business schools with dimensions for defining study objectives and assessing them. He also pointed out that the AACSB avoids specific standards and instead requires business schools to choose, create, and innovate.

Flasdick and Michel (2006) studied and compared the accreditation processes of the AACSB, AMBA, EQUIS, and other organizations. They concluded that organizations follow four basic steps for reviewing accreditation: preparation, application, assessment, and decision. Huang (2005) believes that the accreditation processes for higher education are generally consistent with those for specific professions. They all consist of five steps: setting accreditation standards, self-assessment, field trips, as well as decision-making and reassessment. Although the accreditation patterns of these organizations are overall similar, they individually take different paths to organize a given assessment.

Deng (2005) holds the view that the nature and mission of a professional degree education programme layout largely depends on the maturity of the given profession. In other words, a professional degree can be established only when the profession becomes highly specialized. A professional degree education is essentially a kind of vocational education. White and Mayo (2005) drew the conclusion that practical skills are more important than basic knowledge in student learning and employment. 


\section{Theoretical Framework}

In systems theory and cybernetics, colours are often used to present the degrees of a researchers' understanding of a given system and its internal information. "Black" refers to information that is completely unavailable, while "white" represents information that is completely known. "Grey" is defined as information that is not sufficient, yet not entirely lacking. Therefore, systems with incomplete information are referred to as grey systems. The research object of a grey system is information that is partially known and partially unknown. These grey systems are also referred to as "poor systems" or "uncertain systems". They achieve a precise description and understanding of the real world by generating and exploring known information. In other words, grey system theory is mainly used to clarify unknown information with the help of known information, so as to make grey systems into white systems.

A major feature of this methodology is that there are no strict requirements for sample sizes or the distribution forms that the samples should follow. Social and economic systems have obvious complexity in levels, ambiguity of structural relations, randomness of dynamic changes, imperfections, and uncertainties in indicator data. Multiple factors, including technical methods and human behaviour, can lead to data errors and shortages. Even false data will generate greyness. Due to the ubiquity of grey systems, grey system theory has a great potential for future development in application.

Systems analysis aims to clarify the major and minor factors that affect a system. Traditional systems analysis methods are mostly comprised of mathematical statistical models, such as regression analyses, variance analyses, and principal component analyses. Among them, regression analysis is most commonly used method. However, regression analyses have relatively obvious limitations, such as large sample size requirements, significant distribution, regularity of samples, and large amounts of calculation. Additionally, quantified results can sometimes be inconsistent with the results of qualitative analyses. Grey system theory presents us with a new analysis method, named the grey correlation analysis, which measures the degree of correlation between factors based on the similarities or differences in their developmental status. This method has a relatively low requirement for sample size as well as for distribution and calculation. All random processes are grey processes that change within a certain range. Although they appear complex and chaotic, the results always have some overall functions, orders, and hidden regularities. The basis of grey system theory modelling is generating and accumulating data based on the original chaotic variables, so as to find their approximate exponential laws.

In some situations, researchers are not fully aware of specific factors regarding the assessment object, resulting in a lack of foundation for decision-making. Similarly, researchers can find that the object of study vanishes due to an understanding that lags behind the reality of a situation (because of an object's continuous development and change, for example). A researcher's judgement can also deviate under the influence of false information and disinformation. All of these situations may result in incomplete information; that is, greyness. Grey system theory is a theory for researching and processing complex relations, but doing so while starting with incomplete information. It does not begin with specific regularities within a system, but with the mathematical processing of a given observation at a certain level in the system. This is done to understand the mechanisms inside the systems at a higher level, such as changing trends or mutual relations. Grey correlation analyses are one of the major applications of grey system theory. The grey comprehensive evaluation method is based on the grey correlation analysis, and compares and sorts assessment objects according to specific factors and the degree of relevancy among optimal standards.

The cultivation and education of business talent is a complex system as well as a professional activity that is multi-factored, multi-levelled, and changeable. It concerns all aspects of the students and faculty in a given university programme, representing an entire process. The formation mechanism of a school's quality of education is rather complicated, and often exhibits complexity and greyness in assessment. Practice shows that when used properly, the grey system theory can more effectively utilize known information to improve accuracy of assessment, when compared with the traditional methods. This is in fact an inevitable result, given the characteristics of the grey system theory. In this study, a multi-level comprehensive grey evaluation model is developed and applied in assessing the accreditation awarded by the AMBA to the GDUFS.

\section{Model Specification}

The grey comprehensive evaluation is based primarily on the following model:

$$
R=E \times W
$$

In the formula: $R=\left[r_{1}, r_{1}, \cdots, r_{m}\right]^{T}$, represents the result vector of $m$ objects in the comprehensive assessment. 
$W=\left[\omega_{1}, \omega_{2}, \cdots, \omega_{n}\right]^{T}$, represents the weight distribution vector of $n$ assessment indicators, where

$$
\sum_{j=1}^{n} \omega_{j}=1
$$

$E$ represents the assessment matrix of these indicators:

$E=\left[\begin{array}{cccc}\xi_{1}(1) & \xi_{1}(2) & \cdots & \xi_{1}(n) \\ \xi_{2}(1) & \xi_{2}(2) & \cdots & \xi_{2}(n) \\ \vdots & \vdots & & \vdots \\ \xi_{m}(1) & \xi_{m}(2) & \cdots & \xi_{m}(n)\end{array}\right]$

$\xi_{i}(k)$ presents the correlation coefficient between the $k^{\text {th }}$ indicator and the $k^{\text {th }}$ optimal indicator in the $I^{\text {th }}$ scheme.

Next, the objects are sorted by the values of R.

\subsection{Ascertain the Optimal Indicator Set $\left(F^{*}\right)$}

Assume: $\quad F^{*}=\left[j_{1}^{*}, j_{2}^{*}, \cdots, j_{n}^{*}\right]$

In the formula, $j_{k}^{*}(k=1,2, \cdots, n)$ represents the optimal value of the $k^{\text {th }}$ indicator. This value can be the optimal value among all schemes or the optimal value on which the assessors reach a consensus. In the case of the former, if it is better for the indicator to take a large value, the maximum among all schemes is selected. However, if it is better for the indicator to take a small value, the minimum among all schemes is selected. In the case of the latter, consideration should be given to advancement as well as feasibility. If the optimal value is set too high, it may be impractical and result in incorrect assessment.

After ascertaining the optimal indicator set, matrix $D$ is formatted as:

$$
D=\left[\begin{array}{cccc}
j_{1}^{*} & j_{2}^{*} & \cdots & j_{n}^{*} \\
j_{1}^{1} & j_{2}^{1} & \cdots & j_{n}^{1} \\
\vdots & \vdots & & \vdots \\
j_{1}^{m} & j_{2}^{m} & \cdots & j_{2}^{m}
\end{array}\right]
$$

In this formula, $j_{k}^{i}$ represents the original value of $k^{\text {th }}$ indicator in $I^{\text {th }}$ scheme.

\subsection{Standardize the Indicator Values}

Due to varying dimensions and magnitudes, assessment indicators cannot be compared directly. The original indicator values should be standardized to ensure correctness of assessment.

Assuming the variation section is $\left[j_{k 1}, j_{k 2}\right], j_{k 1}$ is the minimum of the $k^{\text {th }}$ indicator among all schemes, while $j_{k 2}$ represents the maximum. From the formula below, the original value can be transferred to the dimensionless value $C_{k}^{i} \in(0,1)$ :

$C_{k}^{i}=\frac{j_{k}^{i}-j_{k 1}}{j_{k 1}-j_{k}^{i}} \quad i=1,2, \cdots, m ; \quad k=1,2, \cdots, n$

In this way, matrix $D$ is transformed into matrix $C$ :

$$
C=\left[\begin{array}{cccc}
C_{1}^{*} & C_{2}^{*} & \cdots & C_{n}^{*} \\
C_{1}^{1} & C_{2}^{1} & \cdots & C_{n}^{1} \\
\vdots & \vdots & & \vdots \\
C_{1}^{m} & C_{2}^{m} & \cdots & C_{n}^{m}
\end{array}\right]
$$




\subsection{Retrieve the Results of the Comprehensive Assessment Calculation}

According to grey system theory, $\left\{C^{*}\right\}=\left[C_{1}^{*}, C_{2}^{*}, \cdots, C_{n}^{*}\right]$ can be set as the referencing number series, and $\{C\}=\left[C_{1}^{i}, C_{2}^{i}, \cdots, C_{n}^{i}\right]$ can be set as the referenced number series. With that, $\xi_{i}(k)$ can be calculated. The correlation coefficient between the $k^{\text {th }}$ indicator and the $k^{\text {th }}$ optimal indicator in the $I^{\text {th }}$ scheme as follows:

$$
\xi_{i}(k)=\frac{\min _{i} \min _{k}\left|C_{k}^{*}-C_{k}^{i}\right|+\rho \max _{i} \max _{k}\left|C_{k}^{*}-C_{k}^{i}\right|}{\left|C_{k}^{*}-C_{k}^{i}\right|+\rho \max _{i} \max _{k}\left\|C_{k}^{*}-C_{k}^{i}\right\|}
$$

In this formula $\rho \in[0,1]$, and this formula takes $\rho=0.5$.

With the defined value of $\xi_{i}(k)$, the value of $E$ can be calculated.

The assessment result is $R=E \times W$, and therefore:

$$
r_{i}=\sum_{k=1}^{n} W(k) \times \xi_{i}(k)
$$

From the description of the multi-level grey assessment method above, it can be concluded that one of its greatest features is that it classifies the scattered information of different assessors into vectors of different grey clusters, and standardizes those vectors. Except in determining the grades of the assessment object, the results can also be used as the basis for the assessor to sort the values of different grey assessment objects at one time, and can provide suggestions for improving each indicator.

\section{Results and Analysis}

\subsection{Determine the System of Indicators}

With reference to the assessment standards of the AMBA and the method of educational quality assessment, this study establishes systems similar to those of the AMBA. They are presented in Table 1. Based on Delphi's adroit investigation method, selection of systematic indicators complies with the principles of hierarchy, applicability, and comparability. The system covers six first-class indicators, including institution and project management, faculty, students and school systems, curricula, objectives and results, as well as learning model and student participation. It also covers 29 second-class indicators, such as the institution characteristics and kernel system, faculty and teaching quality requirements, student enrolment and teaching systems, course teaching and internationalization, goal attainment and educational value added, as well as interdisciplinary studies and alumni associations.

Table 1. International Accreditation Indicator System of the AMBA

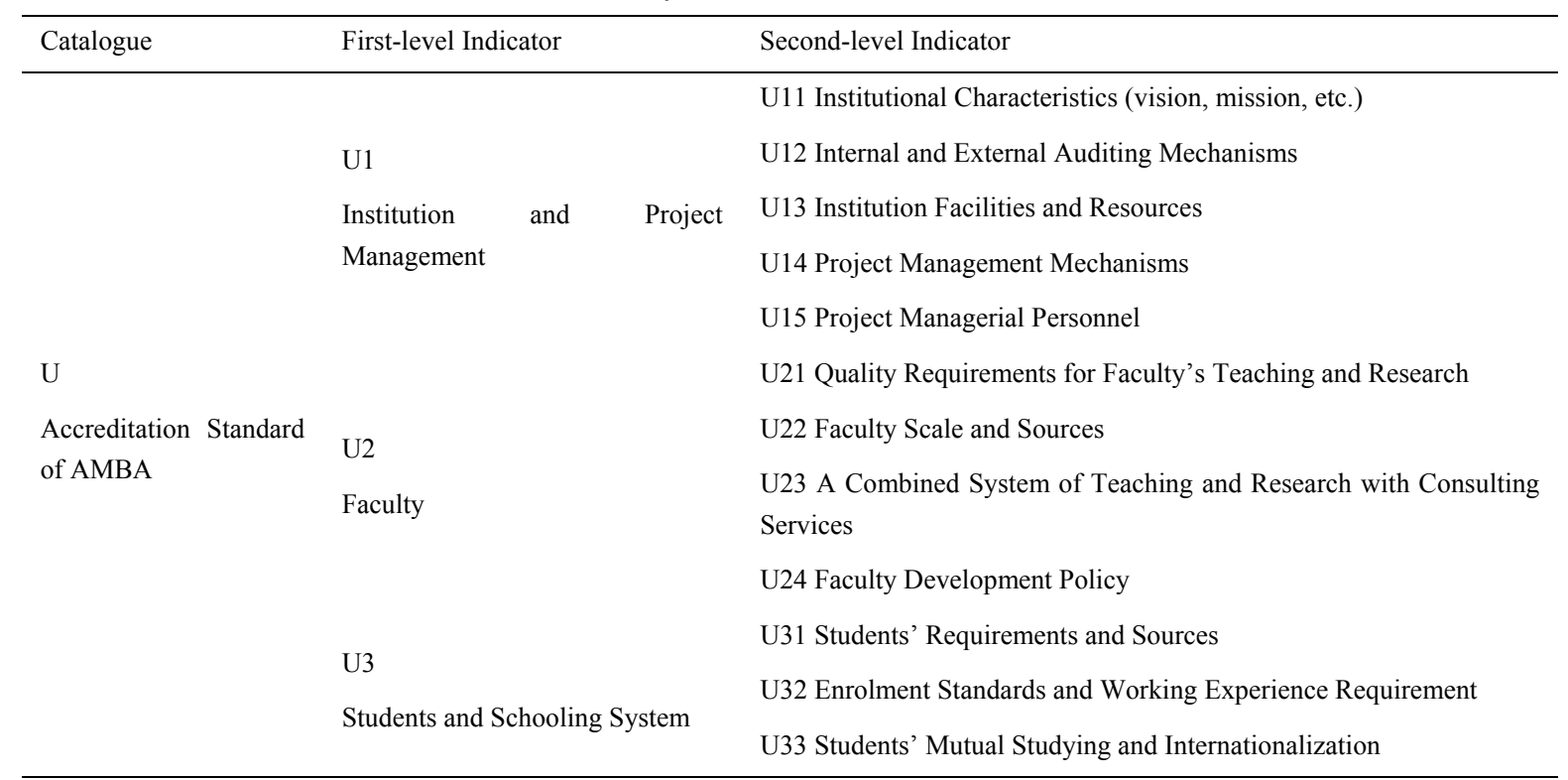


U34 Schooling Standards and Study Time

U35 Teaching Systems

U41 Curriculum Content and Levels

U4

Curriculum

U5

Objectives and Results

U6

Learning Model and Student

Participation
U42 Project Design and Internationalization

U43 Teaching and Studying Methods

U44 Studying of Management Skills

U45 Appraisal Systems and Feedback

U51 Projects Objectives and Highlights

U52 Objective Achievement and Achieving Methods

U53 Employer Expectation Levels

U54 Education's Value Added

U61 Classroom Learning and Online Learning

U62 Multi-disciplinary Learning

U63 Care and Support for Students

U64 Alumni Associations

U65 Continuing Education for Graduates

U66 Social Evaluation

\subsection{Determine the Weights}

The weights are people's judgments on the importance of a given indicator. These judgements are often affected by subjective factors and represent the quantization of a qualitative analysis. Different people tend to have different views on specific things. In their view, there are reasonable aspects as well as aspects biased by personal values, capabilities, and attitudes. Therefore, schemes that are put forward after coordinating the contradictions of assessors, as well as discussing, negotiating, and observing the various actual situations, are typically more convincing.

Based on the structure of the accreditation system of the AMBA, a judgement matrix building on the analytic hierarchy process is established. The matrix has a scale of 1-9. Subsequently, the weight of each indicator is calculated by root methods. Taking relative weights of first-class indicators for objective $U$ as an example, a judgement matrix $U=($ bij) $6 \times 6$ is formed. See Table 2 . Then eigenvectors $W U=(w 1, w 2$, w3, w4, w5, w6) are calculated by root methods as well.

Given level structures, the judgment matrix is constructed on a 1-9 scale, and the weight of each evaluation indicator is calculated by the square root method.

Table 2. First-level vector judgement matrix and relative weight for objective A

\begin{tabular}{cccccccc}
\hline$U$ & $U_{1}$ & $U_{2}$ & $U_{3}$ & $U_{4}$ & $U_{5}$ & $U_{6}$ & $W_{U}$ \\
\hline$U_{1}$ & 1 & 0.3333 & 0.25 & 0.3333 & 0.5 & 0.25 & 0.0563 \\
$U_{2}$ & 3 & 1 & 0.5 & 0.5 & 2 & 0.3333 & 0.1288 \\
$U_{3}$ & 4 & 2 & 1 & 2 & 2 & 0.5 & 0.2295 \\
$U_{4}$ & 3 & 2 & 0.5 & 1 & 2 & 0.5 & 0.1737 \\
$U_{5}$ & 2 & 0.5 & 0.5 & 0.2 & 1 & 0.5 & 0.1023 \\
$U_{6}$ & 4 & 3 & 2 & 2 & 2 & 1 & 0.3094 \\
\hline
\end{tabular}

After a consistency test, $\mathrm{CR}=0.032<0.1$, and $W U=(0.0563,0.1288,0.2295,0.1737,0.1023,0.3094)$, representing each first-class indicator's relative weight vector for objective A. In the same way, relative weight for the second-class indicators for the corresponding first-class indicators is calculated. They are $\mathrm{W}_{\mathrm{t}}(\mathrm{t}=1,2,3,4,5,6)$. 
$\mathrm{W} 1=(0.0816,0.1341,0.354,0.177,0.2533)$

$\mathrm{W} 2=(0.1182,0.1671,0.2616,0.4531)$

$\mathrm{W} 3=(0.2727,0.3762,0.1906,0.0765,0.084)$

$\mathrm{W} 4=(0.0749,0.2195,0.3525,0.2195,0.1336)$

$\mathrm{W} 5=(001603,0.0953,0.2776,0.4668)$

$\mathrm{W} 6=(0.0899,0.1748,0.0636,0.2645,0.1297,0.2775)$

The relative judgement matrices all pass the consistency test $(\mathrm{CR} 1=0.025, \mathrm{CR} 2=0.026, \mathrm{CR} 3=0.057, \mathrm{CR} 4=0.013$, $\mathrm{CR} 5=0.012$, CR6 $=0.017$ ).

\subsection{Determine the Grey Clusters}

According to the actual requirements for the international accreditation of a business school, four grey clusters have been set after consulting experts: $\mathrm{V}=\{$ strong, semi-strong, medium, semi-weak $\}$, and the corresponding grade set $\mathrm{V}=(9,7,5,3)$. Four whitening weight functions are set as seen below. $f_{e}(x)(0 \leq x \leq 10 ; e=1,2,3,4)$ :

$$
\begin{gathered}
f_{1}(x)=\left\{\begin{array}{ll}
\frac{1}{9} x, & x \in[0,9] \\
1, & x \in[9,10]
\end{array} ; f_{2}(x)=\left\{\begin{array}{ll}
\frac{1}{7} x, & x \in[0,7] \\
2-\frac{1}{7} x, & x \in[7,10]
\end{array} ;\right.\right. \\
f_{3}(x)=\left\{\begin{array}{ll}
\frac{1}{5} x, & x \in[0,5] \\
2-\frac{1}{5} x, & x \in[5,10] ; \\
0, & x \notin[0,10]
\end{array} f_{4}(x)= \begin{cases}1, & x \in[0,3] \\
2-\frac{1}{3} x, & x \in[3,6] ; \\
0, & x \in[6,10]\end{cases} \right.
\end{gathered}
$$

\subsection{Calculate the Weight Matrix of the Grey Assessment}

Assuming $d_{l k}^{(t)}$ is the assessment value of $\mathrm{C}_{\mathrm{tk}}$, with the first-level vector $\mathrm{Ut}(\mathrm{t}=1,2, \ldots, 6)$, then the first-class indicator assessment matrix of $\mathrm{U}_{\mathrm{t}}$ is, $D_{t}=\left(d_{l k}^{(t)}\right)_{l \times k} \cdot \mathrm{fe}\left(d_{l k}^{(t)}\right)$ is the weight of $d_{k k}^{(t)}$ in the $e^{\text {th }}$ grey cluster. Additionally, $p_{k e}^{(t)}, p_{k}^{(t)}$ are the coefficients and general coefficient of $C_{t k}$, respectively.

$$
p_{k e}^{(t)}=\sum_{l=1}^{K} f_{e}\left(d_{l k}^{(t)}\right) \quad p_{k}^{(t)}=\sum_{e=1}^{4} p_{k e}^{(t)}
$$

Assuming $r_{k e}^{(t)}$ as the expert assessment weight for $C_{t k}$, then:

$$
r_{k e}^{(t)}=\frac{p_{k e}^{(t)}}{p_{k}^{(t)}}
$$

The weight of $\mathrm{U}_{\mathrm{t}}$ (the $t^{\text {th }}$ first-class indicators, $\left.\mathrm{t}=1,2, \ldots 6\right)$ can form the grey assessment matrix $R_{t}=\left(r_{k e}^{(t)}\right)_{K \times 4}$.

\subsection{Determine the Comprehensive Assessment}

First, assess the $t^{\text {th }}$ first-class indicator, and let the assessment vectors be $\mathrm{U}_{\mathrm{t}}$. Then $\mathrm{U}_{\mathrm{t}}=\mathrm{W}_{\mathrm{t}} \cdot \mathrm{R}_{\mathrm{t}}(\mathrm{t}=1,2, \ldots 6)$, and a grey assessment matrix for objective $\mathrm{U}$ is constructed:

$$
R=\left(U_{1}, \cdots, U_{6}\right)^{\mathrm{T}}
$$

Therefore, the comprehensive assessment vector of assessed teachers is:

\section{$\mathrm{U}=\mathrm{WU} \cdot \mathrm{R}$}

While the comprehensive assessment values are:

$$
\mathrm{U}=\mathrm{WU} \cdot \mathrm{R}
$$


A comprehensive assessment model is built to evaluate quality and satisfaction with the GDUFS MBA degree programme after its accreditation by the AMBA. Questionnaires were sent to supervising departments, professors and experts, students, teachers, and employers to solicit their opinions on the programme. Then, a group of 10 experts was assigned to dig through the model's files and score each indicator according to international accreditation standards. The scoring was conducted on a 10-point scale with a stage difference of 0.5. Taking U3 (Information Resources) as an example, the weight of each indicator is calculated based on assessment matrix D3, whitening weight function fe(x), and Formula (1), and matrix R3 is formed:

$$
R_{3}=\left(\begin{array}{cccc}
0.4203 & 0.3979 & 0.1818 & 0.0 \\
0.4652 & 0.3870 & 0.1478 & 0.0 \\
0.2865 & 0.3610 & 0.3178 & 0.0347 \\
0.2865 & 0.3689 & 0.3267 & 0.0176 \\
0.2794 & 0.3592 & 0.3352 & 0.0262
\end{array}\right)
$$

According to Formula (2), the comprehensive assessment vector of the first-class indicator $\mathrm{U}_{3}$ is:

$$
\mathrm{U} 3=\mathrm{W} 3 \cdot \mathrm{R} 3=(0.3897,0.3813,0.2189,0.0102)
$$

In the same way, the comprehensive assessment vectors can be calculated for $U_{1}, U_{2}, \ldots U_{6}$. Then matrix $R$ is formed based on Formula (3):

$$
R=\left(\begin{array}{cccc}
0.3902 & 0.3997 & 0.2073 & 0.0028 \\
0.2925 & 0.3413 & 0.2924 & 0.0738 \\
0.3897 & 0.3813 & 0.2189 & 0.0102 \\
0.3310 & 0.3691 & 0.2571 & 0.0428 \\
0.3706 & 0.4117 & 0.2177 & 0.0 \\
0.3750 & 0.3930 & 0.2320 & 0.0
\end{array}\right)
$$

If a maximum-weight principle is adhered to, the grey cluster is defined in the satisfied class. However, after calculating the assessment value $\mathrm{W}$ and whitening functions of each grey cluster, the grey clusters to which $\mathrm{W}$ belongs, based on maximum whitening weight, is defined. Thereafter, The GDUFS MBA programme can be classified as semi-strong, according to the standards of the AMBA.

According to Formula (4), the assessment vector of the GDUFS MBA program is:

$$
\mathrm{U}=\mathrm{WU} \cdot \mathrm{R}=(0.3605,0.3818,0.2383,0.0194) \text {. }
$$

According to Formula (5), the comprehensive assessment value $\mathrm{Z}$ is:

$$
\mathrm{Z}=\mathrm{U} \cdot \mathrm{VT}=7.17
$$

Therefore, the overall assessment results in that the GDUFS MBA programme is categorized as semi-strong. Experts and students have recognized this conclusion. The weight vectors of third-level indicators of the MBA programme at GDUFS, indicators including teaching material selection, teacher-student interaction, internal and external practice conditions, academic innovation and entrepreneurship, career guidance and services were below the standards of the AMBA and had room for improvement. Indicators including teaching work ethics, quality of theoretical teaching, teachers' practical skills, social practice, and volunteer service, on the other hand, exceeded the standards. This shows that aspects of the GDUFS MBA programme are recognized by experts as well as students and teachers.

Since the final results of the different assessment levels will be affected by maximum weight, the assessment results might be controlled by a single factor. As such, the whole assessment may be major-factor oriented, deviating from its comprehensive nature. The grey comprehensive evaluation method takes into equal consideration each sample's effect on the final results as possible. Therefore, the results can theoretically conform better to the real nature of a research object. However, the results of fuzzy comprehensive assessment methods are in fact quantified grade remarks that cannot serve as the basis for sorting and selecting assessed objectives. That is a substantial disadvantage for this method.

The results of a grey comprehensive evaluation can not only be used to define the class of a single assessed objective, but can also provide the foundations for sorting and selecting among a group of assessed objectives. Referring to the accreditation system of the AMBA, this report has constructed models and designed a study based on the GDUFS MBA programme with the adoption of a comprehensive assessment method building on the grey system theory. The results conform to the actual situation and can serve as a basis for future decision-making. 


\section{Conclusion}

This report assessed the GDUFS MBA programme with reference to the international accreditation system of the AMBA. During the entire process, it has gained great attention and support from the leadership of the university. The assessment results have proven to be in tune with the reality of the situation through communication with the university's relevant departments, and will provide them with insight for improvement. Through the research conducted in this paper, there is hope that advancing the cultivation of postgraduate education by international standards is promoted further. It is also hoped that this research may provide the basis for colleges to improve their education and services, and encourage proper attitudes toward the professional postgraduate education of MBA students.

In the practice of educational assessment (such as school assessments, teaching assessments, academic achievement evaluations, competition evaluations, and students' moral assessments), a great number of assessment indicators should be taken into consideration. These systems of assessment indicators are usually multi-level, and are given corresponding weights. As such, the multi-level grey assessment method is widely applicable in this field. When used properly, it can more effectively utilize known information to improve the accuracy of assessment, when compared with traditional methods. This is in fact an inevitable result, given the characteristics of the grey system theory. Under certain circumstances, grey assessment methods can be applied together with fuzzy comprehensive evaluations, or other comprehensive assessment methods, to draw more reliable conclusions.

In educational assessment, there is a requirement to use a variety of quantitative tools, but these tools ought not be abused or solely relied on. Quantitative tools should be adopted based on qualitative ones, so as to study the relationships between the quality and quantity of systems with reference to their varying aspects. Quantitative tools should be adopted together with qualitative analysis. In the practice of educational assessment, the quality of systems of education ought to be investigated through initial qualitative analysis and only then be analysed via quantitative analysis. Finally, further research can be inducted and reveal quality on deeper levels, and thus make judgements and conclusions in line with the reality of a given situation.

\section{Acknowledgments}

This research was sponsored by the 2015 Research Project of Graduate Education and Reform of Guangdong Province (2015JGXM-MS23), the 2014 Research Project of Graduate Education and Reform of the Guangdong University of Foreign Studies (14GWYJSJG-02), and the 2016 Research Project of Undergraduate Education of the Guangdong University of Foreign Studies (GWJY2016039).

\section{References}

Alderman, G. (2005). Compliance or quality? American and British approaches to the accreditation of higher education institutions. College and University Institutions, 81(55), 17-23.

Bryant, M., \& Scherer, R. F. (2009). Developing an effective mentor-business school relationship in the AACSB initial accreditation process. American Journal of Business, 24(1), 7-14. https://doi.org/10.1108/19355181200900001

Cheng, G. (2009). A research on assessment systems of enterprises' information service capacity. Library and Information Service, 9, 1390-1393. (in Chinese)

Fang, X. H., \& Chen, M. Y. (2011). A research on the accreditation and assessment systems of web-based education in the United States. Jiangsu Higher Education, 4, 141-146. (in Chinese)

Gao, X. Y., \& Zhang, Y. J. (2009). An analysis of higher education accreditation organizations' standards for colleges in the United States. Studies in Foreign Education, 36(3), 66-71. (in Chinese)

Hua, Y., \& Yu, M. C. (2009). A comprehensive assessment of enterprises' information service capacity based on Fuzzy Analytic Hierarchy Process. Information Science, 9, 1390-1393. (in Chinese)

Jantzen, R. H. (2000). AACSB mission-linked standards: Effects on the accreditation process. Journal of Education for Business, 5, 343-347. https://doi.org/10.1080/08832320009599038

Li, M. H. (2010). A research on revolution trend of higher education accreditation systems in the United States. Fudan Education Forum, 4, 73. (in Chinese)

Nitham, M. H., Mohammad, K. N., \& Abdulrahman, M. J. (2008). An examination of assessment practices in colleges of business at various Middle East countries. International Journal of Teaching and Case Studies, l(4), 319-332. https://doi.org/10.1504/IJTCS.2008.022985 
Scherer, R. F., Javalgi, R. G., \& Bryant, M. (2005). Challenges of AACSB International accreditation for business schools in the United States and Europe. Thunderbird International Business Review, 11, 654-659. https://doi.org/10.1002/tie.20074

Trapnell, J. E. (2007). AACSB International accreditation. Journal of Management Development, 26(1), 67-72. https://doi.org/10.1108/02621710710720112

Trapnell, J. E. (2007). AACSB International accreditation: The value proposition and a look to the future. Journal of Management Development, 26(1), 67-72. https://doi.org/10.1108/02621710710720112

Wang, J. C. (2007). A Research on Higher Education Accreditation Systems in the United States. Beijing: Educational Science Publishing House. (in Chinese)

Wang, J. C. (2007). The implement mechanism and function value analysis of educational accreditation systems in the United States. Research on Comparative Education, 5, 43-47. (in Chinese)

Wang, X. H. (2008). The evolution, structure and power of higher education accreditation systems in the United States. Tsinghua Journal of Education, 6, 85-89. (in Chinese)

White, J. B., \& Levernier, M. P. (2009). AACSB International and the management of its brand: Implications for the future. Journal of Management Development, 28(5), 407-413. https://doi.org/10.1108/02621710910955949

Xiong, G. (2004). An analysis of origins and formation motivation of higher education accreditation systems in the United States. Studies in Foreign Education, 6, 61-64. (in Chinese)

You, Z. R., Yao, L. M., \& Jiang, J. Q. (2010). Characteristics, controversies, implications of higher education accreditation systems in the United States. Studies in Foreign Education, 5, 19-20. (in Chinese)

Zhang, J. R. (2006). The enlightenment of comparison among higher education accreditation systems including AACSB International, AMBA and EQUIS on China's MBA projects. Academic Degrees \& Graduate Education, 6, 74-77. (in Chinese)

Zhang, Z. G., \& Yang, C. (2010). A Study on the formation and development motivation of higher education accreditation systems in the United States. Academic Degrees \& Graduate Education, 5, 68-71. (in Chinese)

\section{Copyrights}

Copyright for this article is retained by the author(s), with first publication rights granted to the journal.

This is an open-access article distributed under the terms and conditions of the Creative Commons Attribution license (http://creativecommons.org/licenses/by/4.0/). 